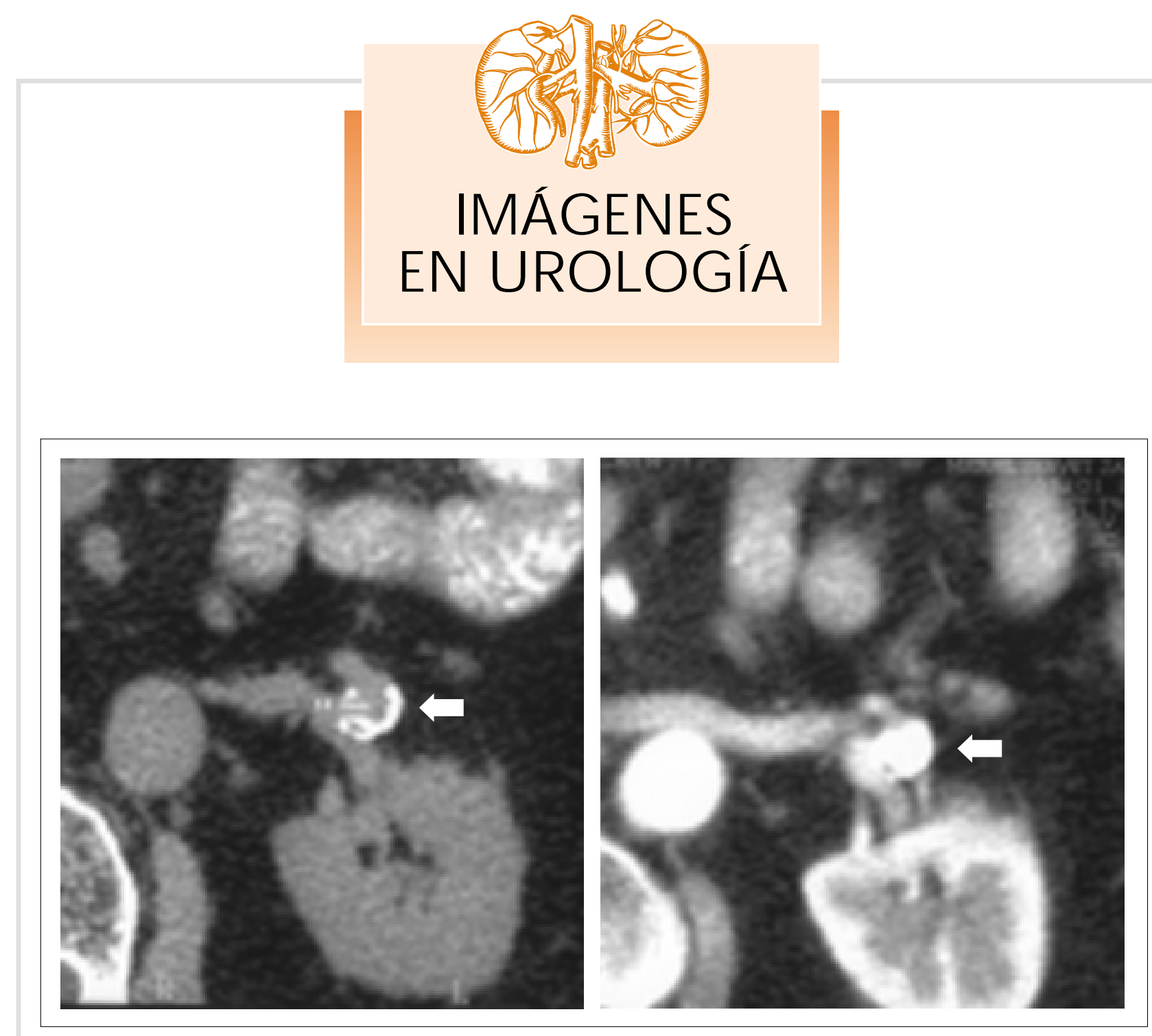

ANEURISMA CALCIFICADO DE LA ARTERIA RENAL. HALLAZGO INCIDENTAL

Varón de 76 años de edad. No antecedentes de interés, no HTA.

Estudiado y controlado por sindrome prostático y en tratamiento con anfabloqueantes, con un tacto rectal grado II y PSA de 2.89.

Ante recrudecimiento de su sintomatología prostática y hallazgo de una litiasis vesical de $2,5 \mathrm{~cm}$ en la radiografia, se completa el estudio preoperatorio con flujometria y ECO.

En el estudio ecográfico se descubre una lesión calcificada en riñón izquierdo planteando la duda de una litiasis renal o bien un quiste calcificado.

Se realiza un estudio con TAC, descubriéndose una lesión calcificada de casi $15 \mathbf{~ m m ~ d e ~}$ tamaño, dependiente de la arteria renal izquierda, diagnosticándose de aneurisma de la arteria renal.

Dada la ausencia de clinica y de repercusión, se plantea tratamiento conservador sobre el aneurisma llevándose a cabo una adenomectomía con cistolitotomia.

D. Pascual Regueiro, A. García de Jalón Martínez, C. Sancho Serrano, E. Mallén Mateo, L.A. Rioja Sanz Servicio de Urología. Hospital Universitario Miguel Servet. Zaragoza. 


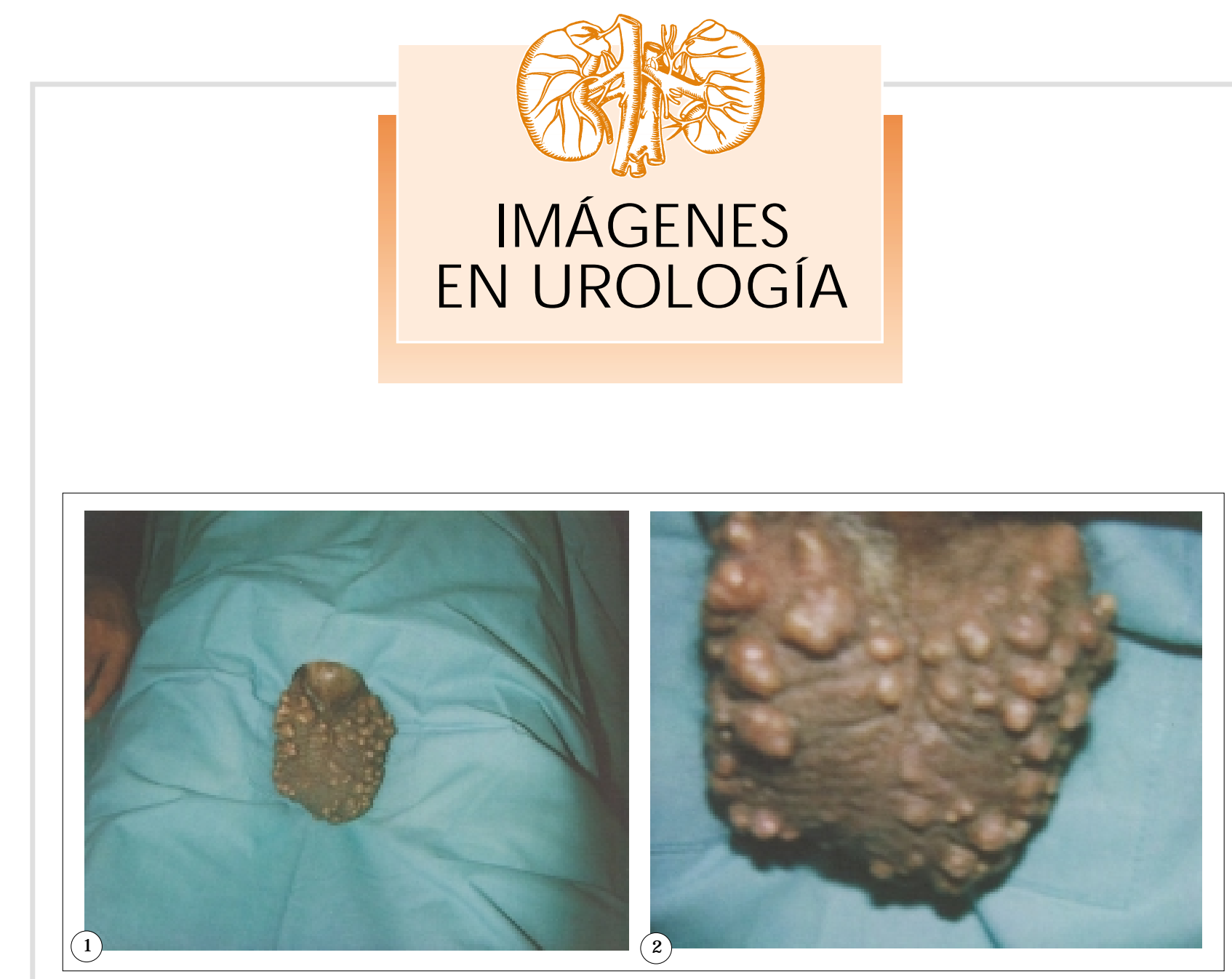

\section{CALCINOSIS ESCROTAL}

Paciente de 72 años en estudio ambulatorio por sindrome miccional.

Durante la inspección se descubren en escroto múltiples quistes, asintomáticos, de más de treinta años de evolución y por los cuales nunca consultó. (Figs. 1 y 2).

A la exploración fisica dichos quistes son de color blanquecino-amarillento, miden de $0,5 \mathrm{~cm}$. a $2 \mathrm{~cm}$. y presentan al tacto una consistencia dura.

Comentario: Esta lesión también denominada Esteatocistoma múltiple es una tumoración cutánea benigna que afecta a varones de edad media.

Su etiologia es desconocida y parece existir cierta tendencia familiar.

Histológicamente se caracteriza por una cápsula, constituida por folículos pilosos y glándulas sebáceas, que limita en su interior una mezcla de grasa, queratina y productos de degradación.

No es rara la sobreinfección y abcesificación de los quistes, que precisarán del drenaje del contenido purulento.

El tratamiento es la extirpación de las lesiones incluyendo la pared del quiste, aunque son frecuentes las recidivas.

J.A. Cuesta Alcalá, J. Aldave Villanueva, A. Solchaga Martínez, I. Pascual Piédrola, J.L. Arrondo Arrondo, L. Ripa Saldías, V. Grasa Lanau, M. Ponz González, A. Ipiens Aznar Servicio de Urología. Hospital de Navarra. Pamplona. 